\title{
Evaluation of Vocational High School Teachers' Concern in Implementing Curriculum 2013
}

\author{
Nizwardi Jalinus ${ }^{\mathrm{a}, 1}$, Youmil Abrian ${ }^{\mathrm{a}}$ \\ ${ }^{a}$ Engineering Faculty, Padang State University, Padang, INDONESIA \\ ${ }^{1}$ nizwardi@unp.ac.id
}

\begin{abstract}
This paper aims to assess the extent to which the elements of concern of teachers to the change of curriculum. Problems that always arise in the process of change is the only change into a document, while the implementation of the provision of education and learning for the new curriculum as it is still ongoing. Statement of the problem in this study is how the profile of teachers'stage of concern in implementing curriculum 2013.45 teachers of Vocational High School 6 Padang were selected to be representative respondents. The Stages of Concern Questionaire was used to collect data of teachers concerns over the changes in implementing curriculum 2013. The findings revealed that the most teachers' concern profiles over the implementation of the curriculum in 2013 have highest intensity of concern on the stages of consequence. Comparison of the stages of concern among teachers based on areas of expertise as well as teaching experience provide valuable information for futher improvement of curriculum implementation.
\end{abstract}

Index Terms - teachers' concern, evaluation, curriculum implementation and vocational high schools.

\section{Introduction}

Vocational education plays an important role to educate and train the younger generation to face globalization, technological change, economic competition, social and cultural changes affecting community life. Vocational education in Indonesia has the responsibility to educate and train them to be productive workforces, which must be able to compete in the global world.

Vocational teachers as the spearhead of education and training, particularly productive field of vocational technology teachers are required to be more professional. Data (PMK, 2013) shown that teachers who teach vocational expertise in SMK only 13,500 teachers, while from the current school to day, 35,000 vocational teachers are needed to fill the 128 competency skills developed at this time in Vocational High Schools. Teachers have important roles to implement innovation and change their teaching strategy and approach, then the productive effort to prepare the younger generation will undoubtedly superior.

Indonesian government through documents of Minister of Education and Culture (Permendikbud) has published a new curriculum, it is the curriculum 2013. Some regulations have issued a juridical basis for the planning, implementation and monitoring of the new curriculum, which are Permendikbud no.70 in 2013 on the structure and curriculum framework. Permendikbud No. 81 A 2013, is a bout implementation of the curriculum in 2013, and some others regulations concerning standards relate to education, such as competency standards, curriculum content standards, standard of process, standard of facilities and infrastructure, and standards of evaluation and assessment.
The teacher is spearheading a change in the education and learning process, because teachers are indeed directly interact with the students. Fullan (1991.77) stated that the role of teachers individually and collegially plays a decisive role in the implementation of the curriculum [1]. There are obstacles in the implementation of new curriculum barriers associated with being a teacher, a factor needs, concerns, socialization, clarity of changes, teaching materials, good practice facilities reflected in the amount and quality of existing machinery and equipment, the support of Local Goverment in the management of schools as well as the quality of teachers performance. Those all need to be standardized.

The problem of teachers commonly appeared comes from outside or inside of teacher itself, it may be true, but which need to be observed psychological factors behind it, the teacher looked at all the flaws are beyond him. This seems simple, but the implementation of the curriculum could have broad impact. Maybe it can happen "teachers can not simply be able to implement the changes and not able to overcome the obstacles and try to eliminate or at least minimize the consequences of the changes. The implications of such a state of "curriculum was limited to documents, with service learning to survive in the habits of the past". Therefore, the implementation plan has been designed to be intensive in order to monitor the changes that are expected to be achieved. Logistical and moral support from the local government, department heads, principals as initiator and manager of changes as an actor and teacher in the classroom changes play very important role. Change of teachers mindset and students will adjust.

Based on the results of a survey on the implementation of the curriculum in 2013 was reported by newspaper that the implementation of the curriculum fate having a lot of problems, mainly related to the preparation of a less mature as revealed by Itje Chodijah in news paper Kompas, a lack of coordination between the initial design with good technical team to look assessment system, create doubt and confuse [2] . Curriculum 2013 survey conducted by FSGI (United Federation of Teachers Indonesia) stated that the original plan there are $30 \%$ of schools that will be pilot testing to implement the curriculum 2013, in fact only $2 \%$ of schools throughout Indonesia. While the survey results of teachers' knowledge about the content of the curriculum in 2013 stated that the majority of teachers do not understand about the curriculum in 2013 , only about $40 \%$ are aware of the new curriculum. The result of implementation of the curriculum 2013 was encouraging, and received a positive response that makes them more confident to implement in all schools next year [3]. The results of this survey has been criticized by the House of Representatives. They comment that the survey should be carried out by independent parties. 
With regard to this situation, although the vocational curriculum specifically for the new 2013 is a new pilot project and implemented during the year, but need to be evaluated, to determine the extent of understanding, thoughtfulness and concern of vocational teachers about curriculum changes in 2013, One of the models which has been widely used is the CBAM.

Concern Based Adoption Model (CBAM) is a model of the adoption of the changes, which measures a person's level of awareness to something new, whether it is a new program, a new policy, innovation, or new curriculum requirements to change. "The CBAM is used to Evaluate a model of curricular innovation and reforms. Cliented It is a centered approach that demonstrates how individuals affected by the change react to the implementation of the innovation" [4]. CBAM was chosen as a model for adoption in this study because CBAM has been used widely in various countries by the researchers, because it is very helpful to improve the understanding of the process of individual change to implement a research-based innovations, such as Casel (Collaborative for Academic, Social and Emotional Learning and LLS (Laboratory for Student Success) using CBAM in 2003 [5]. Measuring Stages of Concern is one of the CBAM diagnoses.

Stages of concern will illustrate the relative intensity of the state of teachers for each level of concern for the implementation of changes. Stages of Concern can be interpreted as a stage of awareness or concern to something new. Hall et. al. defines concerned as "the composite representation of the feelings, preoccupation, thought, and consideration give to a particular issue or task"[6]. The concern can be defined as "expression of feelings, thoughts, seriousness (intensity), consideration of a change". in this case the extent of sense, mind, intensity, and consideration of teachers on the implementation of curriculum 2013. The seven stages of concern(Stages of Concern) against an amendment as follows: Concern consists of 4 categories:[6] [7]

Table 1. Concept of Stages of Concern [7]

\begin{tabular}{|c|c|c|c|}
\hline No & Category & $\begin{array}{l}\text { Stages of } \\
\text { Concern }\end{array}$ & Meaning \\
\hline 1 & Unrelated & $\begin{array}{l}\text { SoC0 - } \\
\text { Awareness }\end{array}$ & $\begin{array}{l}\text { Little concern about } \\
\text { or involvement with the } \\
\text { innovation is Indicated }\end{array}$ \\
\hline \multirow[t]{2}{*}{2} & $\begin{array}{l}\text { Self } \\
\text { Concern }\end{array}$ & $\begin{array}{l}\text { SoC1- } \\
\text { informational }\end{array}$ & $\begin{array}{l}\text { A general awareness of the } \\
\text { curriculum implementation } \\
\text { and interest in learning more } \\
\text { detail about it is Indicated. }\end{array}$ \\
\hline & & $\begin{array}{l}\text { SoC2- } \\
\text { personal }\end{array}$ & $\begin{array}{l}\text { Individual is uncertain about } \\
\text { the demands of the curriculum } \\
\text { implementation, his or her } \\
\text { adequacy to meet those } \\
\text { demands. The individualis } \\
\text { analyzinghis or her } \\
\text { relationshipto the reward } \\
\text { structure od the organization. }\end{array}$ \\
\hline 3 & $\begin{array}{l}\text { Task } \\
\text { Concern }\end{array}$ & $\begin{array}{l}\text { SoC3- } \\
\text { Management }\end{array}$ & $\begin{array}{l}\text { Attention is focused on the } \\
\text { processes and tasks of using } \\
\text { the best practice, and the best } \\
\text { use of information }\end{array}$ \\
\hline
\end{tabular}

and resources. Issues related to efficiency, organization, management, scheduling, and time demands are the utmost concern. .

4 Impact $\quad \begin{aligned} & \text { SoC4- } \\ & \text { Consequence }\end{aligned}$

SoC5-

Collaboration

SoC6-Refocusing
Attention focuses on impact of the implementation to student in his or her immediate sphere of influence. The focus is on relevance of the practice for students, evaluation of student outcomes, Including performance and competencies, and change needed to increase of student outcomed.

The focus is on coordination and cooperation with others regarding use of the innovation.

The focus is on exploration of
more universal benefits from
the innovation, Including the
possibility of major changes or
replacement with more
powerful
alternative. Individual has
difinite ideas about alternative
to the proposed or existing
form of the innovation.

Relative intensity of concern will be reflected in every stages of concern of teachers ' profile, SoC0, SoC1, SoC2, SoC3, SoC4, SoC5, and SoC6. The seventh stages is the profile figuration of caring teachers in implementing the changes in the implementation of the curriculum 2013.

The problem can be sated as "How Profile of vocational teachers' Stages of Concern over the implementation of curriculum 2013" The formulation of this problem is studied in this research. Specifically this study will reveal the profile of vocational teachers' stages of concern in implementing a new curriculum in 2013, which laden with fundamental changes .

The purpose of this study is to Evaluate the teachers' concerns about how they Implemented the new curriculum, and this evaluation figure out the profile of the stages of concern of teachers in terms of implementing the curriculum changes, the result of this research can be used as information to improved the quality of curriculum implementation 2013.

\section{Methods}

This study was a quantitative descriptive survey type. Data collection was carried out by examining the stages of concern (SoC) Vocational High School teachers. The SoC questionnaire was used as data collection instruments. Population and sample is SMKN 6 Padang which had been designated by the government as a pilot 
project in 2013. A total of 45 teachers were selected randomly out of 87 teachers in SMKN6 Padang. These were representative of three programs of expertise in SMKN6. The data collected was processed using quantitative descriptive statistics where the raw data is analyzed and converted to percentile score. Description of the percentile scores for each stage of concern is a state profile of teachers in implementing the changes in the concept of curriculum 2013 implementation .

Measurement of the level of concern by adopting a model CBAM [7], in particular The Stages of Concern Questionnaire (SoCQ). Questionnaire was translated and validated through professional prooffreader, then the SoCq was pilot tested and the result of analyses showed that the cronbach's alpha was 0,8780 for all stages. Descriptive statistics with central tendency were used to measure frequency, mean and standard deviation. The mean of raw score were converted to percentile score as intensity relative of stages of concern.

\section{Results and Discussion}

Table 1. shows a distribution of frequency and percentages of teachers in relation to their Program of study and teachers experiences. Its figure out that total respondent of 45 teachers from SMKN6 Padang were selected to respond the SoC questionnaire, It can be seen that 19 teachers or $42,2 \%$ percent of teachers are from Cosmetology and beauty, and 14 teacherts (31,2\% )of teachers were from the Dress Design and fashion, and 12 teachers were from Food and Culinary departement. Table 1, also shows a distribution of teachers based on their teaching experience. It is divided into four levels ( 0 - $5 \mathrm{yrs}, 5$ - 10 yrs, $10-15 \mathrm{yrs},>15 \mathrm{yrs}-20$, and $>20$ years). It shows that schools predominantly included teachers with more than 20 years teaching experience $(48,88 \%)$ and staff with between 15 to 20 years teaching experience (20\%), 10 to 15 years teaching experiences is about 12 teachers or $26,66 \%$. and only 2 teachers $(4,4 \%)$ who have $0-5$ years teaching experiences.Generally, it can be said that most are highly experienced teachers .

Table2. Distribution of Teachers Bio-data in SMKN6 Padang

\begin{tabular}{llll}
\hline No & Description & Frequency & percentagrs \\
\hline 1 & Program of study & & \\
& 1. cosmetology and beauty & 19 & $42,2 \%$ \\
& 2. Dress Design \& fashion & 14 & $31.2 \%$ \\
& 3. Food \& culinary & 12 & 26.6 \\
& Total & 45 & $100 \%$ \\
2 & Teacher's experiences & 2 & \\
& 0 - 5 years & 0 & $4,44 \%$ \\
& 5 - 10 years & 12 & 0 \\
& $10-15$ years & 9 & $26.66 \%$ \\
& $>15$ - 20 years & 22 & $20,00 \%$ \\
& $>$ 20 years & 45 & $48,88 \%$ \\
& Total & & $100 \%$ \\
\hline
\end{tabular}

\section{a. Teachers' SoC profiles}

The mean scores which were converted into percentiles for each stage of concern from SoC0 to SoC6 indicate the relative intensity of concern of teachers. Figure 1. depicts the SoC profiles of teachers of SMKN6 Padang. It was found that the highest relative intensity of teachers is at point SoC4 (63) or at the level of consequence, and the second highest point is SoC3 management.

The meaning of this profile can be describe as follow . The highest intensity of concequence stages means that teachers are indicated have desire to know the effect of new curriculum implementation to students. Do they change or not, how about student achievement, is there any gain scores of student achievement. These all questions appear in teachers' feeling. As a combination the second highest point is at management stage, it indicates that teachers need support to manage their work, such as logistic or may be need more time to do so.

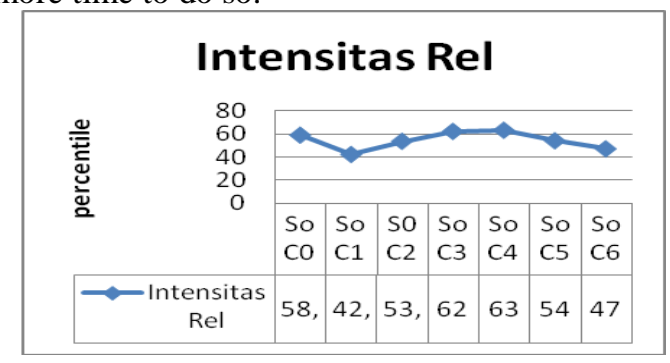

Fig.1. Teachers' SoC Profile of SMKN 6 Padang

\section{b. Teachers SoC profiles based on Program of expertises}

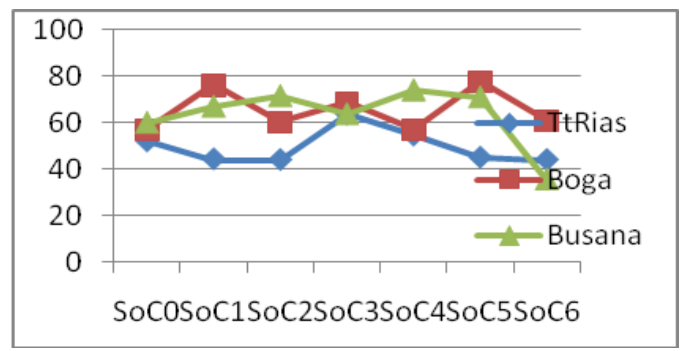

Fig. 2. Teachers' SoC Profile on Program of Expertises

Three SoC profiles are shown in Fig. 2, which provide essential information about teachers' concern in relation to their program of studies. The data can be described as follows:

1. Cosmetology and beauty teachers' SoC profiles show that the highest point is SoC3(management). This can be taken to mean that teachers tend to pay close attention to the organisation, management and effectiveness of the innovation. They need support from leader of management to assist them in term of logistic and time as well as provide the facilities them to manage their use of innovation.

2. The highest relative intensity for food and culinary teachers' SoC profiles is at SoC 5 (collaboration). The second peak point is SoC 1 (informational). These indicate that teachers's most intense concern about the changes in implementing curriculum 2013, and care about the colaboration with others in using it, and they needs more information about it.

3. Dress design and fashion teachers profile indicates three highest intesities, namely, SoC4, SoC5 and SoC2. These can be describes that teachers commonly care about the effects of changes on students, and also need coordination with other teachers. Although they have 
intense personal concerns about the changes and consequences for them, they do not indicate resistence.

\section{Teachers SoC Profiles based on Teaching Experiences}

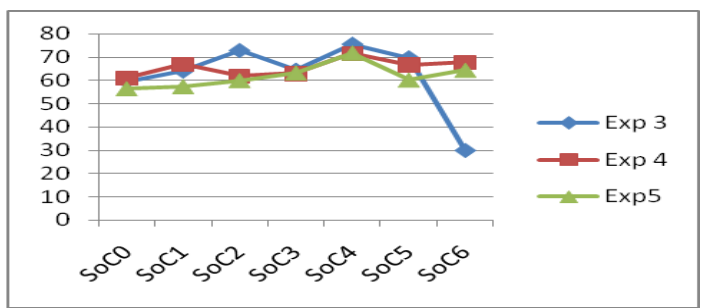

Fig. 3. Teachers SoC Profile Based on Teaching Experiences

Figure 3. shows the SoC profiles on the basis of teaching experience. The range of teaching experience is divided into three subgroups, 11 to 15 years (Exp 3), > 15 to 20 years (exp4), and .over 20 years teaching experiences (exp 5). Actually, on the basis of teaching experiences, the instrument of bio-data divided the years of teaching experiences into 5 subgroups, but only three of subgroups data meet the requirement analysis.

Three subgroups of teachers's teaching experiences are apparent in this graph. First, the SoC profile of teachers who have 11 to 15 years (exp3) experiences. They have highest intense at SoC4 and SoC2. Its indicate that they concern about the effects of curriculum changes on students, but they also feel that the changes have any consequences for themselves. The second subgroup, teachers with $>15$ to 20 years (Exp 4) teaching experiences. The profile of concerns shows that the highes point of intense also in SoC4 and SoC1. Although they concern about the consequences of changes on students, but they still need more information about the changes in implementation of curriculum 2013. Third subgroup, teachers with $>20$ years experiences (Exp5), It is a predominantly subgroup in SMKN6 Padang that they have equal peak point at the SoC4, the others points are in average. Generally, they are on consequence stage, they are willing to know the effect of the changes of curriculum 2013 on their students.

Generally, The SoC profile of SMKN6 Padang 's teachers indicate that they have been implementing the new curriculum with all changes and innovations of curriculum standards, and they have already on the stage of consequence, they are willing to know the effect of the changes to their students, espesially, the impact to the students achievement, to the students behaviour, as well as their character, and also do they learning culture changes ?. Impact concerns describe our thoughts on how we can make a program work better for learners [8]. So it can be said that as recomended by Hall that the focus of teachers is on relevance of the practice for students, evaluation of student outcomes, including performance and competencies, and changes need to increase student outcomes [4]. As a combination it also can be described that teachers also tend to manage themselves in preparing reflection as an feedback of students' impact. Because at this SoC profile depicted the high intensity also at SoC3, its meant that the attention is also focused on the practice of changes.

A comparison of SoC profiles of Three programs of expertise, namely Cosmetology and Beauty(CB), Dress design and fashion(DdF), and Food and Culinary(FC). Based on the profiles of SoC graph, there are different peak points of profiles. Cosmetology and beauty program more intensity of concern at the stage of management, eventhough this point meets the point of Dress design and fashion, but it is not the peak point of its. The highest intensity of Dress design and fashion program is SoC4 (consequence) and follow by SoC5 and SoC2. While the program of Food and Culinary has peak point at SoC5 and SoC1. The profiles described that the program of DdF and FC look like similar ,eventhough its have different peak point. but It is different with the SoC profile of $\mathrm{CB}$. The SoC profile of $\mathrm{CB}$ relatively has lower intensity in comparison with the others two. Exceptionally, only in SoC0 and SoC3, all programs of expertise have similar intensities of concern.

So Its can be conclude that all of programs of expertise in SMKN6 Padang have different peak points of SoC. Program $\mathrm{CB}$ is more concern to manage the changes, paticularly in term of logistic, time and provide the facilities of changes. Facilitator of changes like principle of school should support teachers to implement the changes in curriculum 2013. However, The Program of CB is in task category. It means that all teachers in this program are doing the changes of curriculum 2013. While others are one step ahead, they are in impact category. The process emergence and resolution of concern is highly personal and require time as well as timely intervention for both cognitive and affective factors [7]. They are all teachers from all programs are on the way process in implementing the changes of curriculum 2013. They need support and time from leadership and management, from facilitator of changes to improve their performance toward the inplementation of curriculum 2013.

The SoC profiles of teachers on the basis of teaching experiences tend to be equal, they have similar peak points. They are in SoC4 or on the stage of consequence. So they are willing to know the effect of changes to their students, such as student's achievenent, students's activities, attitudes as well as their culture of leaning. Most of the teachers are experienced teachers in SMKN 6 Padang, actually only two inexperienced teachers in that school, most of them have been teaching more than 11 years. The SoCQ to evaluate inservice teachers concerns about the issue of technology integration. They found that experienced teachers had consequence concerns to students. This is also supported by [5] that "More experiences teachers in teaching may behave more positively toward the implementation of the innovation. Because they have more expertise, more knowledge, skills and understanding and more intense of the concern, regarding the implementation of the innovation". [9] stated that teachers with more experience were higher impact concern toward the implementation of the information technology curriculum in Kuwait. But, in another case, [10], they measured the stages of concern of teachers in integrating e - learning reported that teachers with $1-5$ years teaching experience were placed at the stage of colaboration.

\section{Conclusions}

The major conclusion which may be drawn from the results summarized that teachers in SMKN6 Padang have been involving actively concerning implementation of 
curriculum 2013. Most vocational teachers are at the Stage of consequence(SoC4) in the implementation of the innovation of curriculum SMK 2013. They are at task category toward the innovation. So all of them are user of changes, they are willing to know the effect of the changes to their students, espesially, the impact to the students achievement, to the students behaviour, as well as their character, and also do they learning culture changes.

Three programs of expertise in SMKN6 Padang have different peak points of SoC. Program CB is more concern to manage the changes(SoC3), paticularly in term of logistic, time and provide the facilities of changes. It is in task category. While others are one step ahead, they are in impact category. They are on the way to look into the impact of changes to the students, and try to cooperative with other programs in order to improve the quality of their changes in implementing curriculum 2013.

The SoC profile of teachers based on their teaching experiences tend to be equal relatively. The highest intensity of concerns is on the stage of consequence (SoC4), They all have experiences of teaching more than 11 years. So, after one year implementation of curriculum 2013, most of experience teachers are on impact category. Its mean that esperienced teachers can be recomended to be agent of changes.

Implication of this evaluation is valuable findings to improve a proces of implementation, and can be usefull to improve the quality of implementation for the future. Futher study can be developed to investigate the level of use of the innovation in implementing curriculum 2013.

\section{References}

[1] Fullan. M.G, Stigerlbauer. S. (1991). The New Meaning of educational Change, 2nd Ed. New York : Teacher College Press.

[2] Kompas.com. (2014). Penerapan Kuriklum 2013 Hanya Sekedar Formalitas Kamis 2 Januari 2014.

[3] Kemendikbud. (2014). Paparan Menteri Pendidikan dan Kebudayaan RI. Press Workshop ; Implementasi Kurikulum 2013. Jakarta: Antara News.

[4] Hall, G, E. \& Hord,S, M. (2006). Implementing Change: Patter Principles and potholes (2nd ed). Boston :Allyn and Bacon.

[5] Jalinus. N. (1998).A study of vocational teachers in implementing an innovation in Technical High Schools in Padang and Bukittinggi West Sumatra (Disertation, University of Tasmania ).

[6] Hall, G, E. George, A \& Rutherford,W, L. (1987). Measduring Stages of Concern About The Innovation ; A manual for use of the SoC questioner. Austin TX: The University of Texas.

[7] George.A,A. Hall, G,E.\& Stiegelbauer,S,M. (2013).Measuring Implementation in Schools: The Stages of Concern Questionaire. Austin TX : SEDL

[8] Donals L.Horsley and Susan Loucks Horsley (1998) CBAM Brings Order to The Tornado of Change .Journal of Staff Development Fall 1998 Vol.19.No.4.

[9] Alshamari, B,S.(2000) The Developmental Stages Of Concern Of Teachers Toward The Implementation Of The Information technology Curriculum In Kuwait.(Dissertation, University of North Texas)

[10] Rawajihfih,K,A,. Fong,S,F. \& Idros,S,H,S : Stages of Concernin Integrating E- Learning in Discovery Schools. Asean Social Science journal. $6.54-63.2010$ 